\title{
In vitro comparison of commercial and ultrafine-grained titanium osteosynthesis miniplates used on mandibular fractures
}

\author{
Hojjat Ghahramanzadeh Asl ${ }^{1, A-F}$, Akgün Alsaran ${ }^{2, A, C}$ \\ ${ }^{1}$ Department of Mechanical Engineering Department, Karadeniz Technical University, Trabzon, Turkey \\ ${ }^{2}$ Independent researcher, Eskişehir, Turkey \\ A - research concept and design; $\mathrm{B}$ - collection and/or assembly of data; $\mathrm{C}$ - data analysis and interpretation; \\ $D$ - writing the article; $E$ - critical revision of the article; $F$ - final approval of the article
}

Address for correspondence

Hojjat Ghahramanzadeh Asl

E-mail: h.kahramanzade@ktu.edu.tr

Funding sources

Scientific Research Projects of Atatürk University in Erzurum, Turkey (project No.2013/98).

Conflict of interest

None declared

Acknowledgements

This study was derived from a doctoral thesis, defended on January 28, 2016. The authors wish to thank the TST Medical Devices for miniplate geometries. We also would like to thank Dr. Gençağa Pürçek for permitting us to use the mechanical engineering laboratory facilities in Karadeniz Technical University in Trabzon, Turkey. Hojjat Ghahramanzadeh AsI would like to thank the Scientific and Technological Research Council of Turkey (TÜBiTAK) for the Directorate of Science Fellowships and Grant Programmes (BIDEB) 2215 Scholarship.

Received on April 17, 2020

Reviewed on May 20, 2020

Accepted on June 13, 2020

Published online on December 31, 2020

Cite as

Ghahramanzadeh Asl H, Alsaran A. In vitro comparison

of commercial and ultrafine-grained titanium osteosynthesis

miniplates used on mandibular fractures. Dent Med Probl.

2020;57(4):351-358. doi:10.17219/dmp/123932

DOI

$10.17219 / \mathrm{dmp} / 123932$

Copyright

๑ 2020 by Wroclaw Medical University

This is an article distributed under the terms of the

Creative Commons Attribution 3.0 Unported License (CC BY 3.0)

(https://creativecommons.org/licenses/by/3.0/).

\begin{abstract}
Background. Implants called miniplates, with different geometries, are used for the treatment of a fractured or diseased mandible. Generally, Ti-based miniplates in various quantities and with various geometries are fixed into the bone tissue according to the location and shape of the fracture by embedding.

Objectives. The aim of this study was to increase the strength of the material used in the production of miniplates by means of the equal-channel angular pressing (ECAP) treatment, and to provide a highrigidity fixation system with fewer miniplates.
\end{abstract}

Material and methods. In this study, the ECAP method, which is one of the methods of severe plastic deformation, was applied at 4 passes at $300^{\circ} \mathrm{C}$ in route $\mathrm{Bc}$ to increase the strength of pure Ti. Then, miniplates were produced with 2 different geometries (regular and long) and 2 different properties of the Ti material (untreated and ECAP-treated). The produced miniplates were placed in the fracture line formed in the angular region of an artificial, synthetic-bone mandible. The 2-point and 3-point bending and torsion tests were conducted on these fixation systems.

Results. As a result, after the ECAP process, the yield and tensile strength of pure Ti increased by $65 \%$, while elongation decreased by $13 \%$. After the ECAP process, the grain size of the material was reduced from $110 \mu \mathrm{m}$ to $200 \mathrm{~nm}$.

Conclusions. This study showed that the fixation system became more rigid due to using ECAP-treated miniplates, and this ensured lesser displacement of the fixation system.

Key words: equal-channel angular pressing, bending, torsion, mandible fracture, miniplate 


\section{Introduction}

Today, biomaterials are frequently used in healing the fractures of the mandible caused by diseases, accidents and war. Diseases and fractures in the mandible are found in the condyle, body, angle, symphysis, alveolar bone, and coronoid regions. Metal implants called miniplates, with different geometries, are used for treatment. In the angular region, which is one of the most frequently fractured regions in the mandible, fixations are applied using different geometries and various numbers of miniplates and screws according to the fracture type and size. It is also considered to be more advantageous to use a single miniplate in the fixation system. In the literature, the advantage of using a single miniplate has been noted by researchers as minimal dissection and a reduction in the volume of the implanted material. ${ }^{1-4}$

The most important issue in the case of miniplates, which are usually made of $\mathrm{Ti}$ and its alloys, is the rigidity of the fixation formed. ${ }^{5-10}$ Esen et al. studied different types of plates and fixation systems under different loads by mounting miniplates on angle fractures in sheep mandibles. ${ }^{11}$ As a result, the Ti plate/screw system proved to be the most reliable system for fixation in mandible angle fractures. In that study, it was also stated that if the rigidity of the fixation system is excessive, more load should be applied to break the fracture areas of the mandible. ${ }^{11}$ The mechanical fixation system formed by plates on a mandible bone fracture has been investigated in the literature, mostly in terms of the plate geometry and the bone fixation method. In a majority of studies, miniplates are placed on a sheep mandible or an artificial mandible, and then compared with regard to the displacement values under a certain load. The main aim of such studies is to determine which type of plate is more durable in terms of both geometry and mandible placement. ${ }^{5,12-15}$ When displacement is low, the broken parts of the mandible are hardly separated from each other, and therefore the fixation system exhibits more rigid behavior. For example, when the number of screws or miniplates is increased, the fixation becomes more rigid. ${ }^{16}$

Due to the fact that miniplates are often mounted by embedding them into the bone tissue, an important consideration is the number of miniplates. When the number of miniplates is increased, the surgical area expands, and the duration of the treatment is also prolonged. For this reason, it is important to establish the most rigid fixation system with minimum miniplate usage. This can be achieved by making the fixation with a more durable material or by increasing the strength of the material used. Miniplates are generally manufactured from commercially pure (CP) Ti grade 2 or grade 4 . These materials are suitable in terms of biocompatibility, but they are ineligible in terms of strength. In order to overcome this deficiency, the equal-channel angular pressing (ECAP) mechanical process is preferred.
Severe plastic deformation (SPD) techniques are used to increase the strength of different types of materials. A commonly used SPD method is ECAP. ${ }^{17}$ This method is based on the principles of increasing grain density and dislocation density in massive forms. It was first proposed by Segel et al. in 1977. acc.18 The ECAP method begins with passing the material through 2 channels of an identical cross-section. During this transition, plastic deformation occurs in the inner structure of the material due to a simple sliding mechanism; then, the grain size decreases. ${ }^{19,20}$ One of the characteristics that stands out in this method is that the material becomes ultrafine-grained (UFG), which increases its strength and does not cause severe decreases in its ductility. ${ }^{17,19,21}$ Valiev et al. proved the cell compatibility of pure UFG Ti and its usage as an implant material. ${ }^{22,23}$ There are also studies indicating that the biocompatibility properties of the material may improve after the ECAP treatment. ${ }^{24,25}$

The manufacturing of UFG-structured $\mathrm{Ti}$ miniplates and the fixations made from these structures have not been biomechanically evaluated by researchers. The use of the ECAP method in miniplate-like implant applications will contribute to similar work being done. For this reason, the main purpose of this study was to examine the biomechanical performance of UFG-structured Ti miniplate fixations under static conditions. The aim of this study was to create a more rigid fixation system by increasing the strength of the material used in the production of miniplates by means of the ECAP treatment. At the same time, providing high rigidity with the use of fewer miniplates is the other main purpose of this study. To this end, first, the strength of pure Ti was increased using the ECAP method, and then miniplates with 2 different geometries were produced. The structural and mechanical analyses of the coarse-grained (CG) and UFG structures were performed. To achieve this, the 2-point and 3-point bending and torsion tests were conducted on the fixative models which were formed on the mandible. The particle size and surface topography were investigated using scanning electron microscopy (SEM), the focused ion beam (FIB) technique, transmission electron microscopy (TEM), and optical microscopy (OM).

\section{Material and methods}

The material selected for this study was CP Ti grade 2 with a composition of wt $\%, 0.030 \% \mathrm{~N}, 0.100 \% \mathrm{C}$, $0.015 \% \mathrm{H}, 0.300 \% \mathrm{Fe}$, and $0.250 \% \mathrm{O}$. The material was received in a hot-rolled and annealed condition, with the initial average grain size of $\sim 110 \mu \mathrm{m}$. The ECAP billets of a length of $130 \mathrm{~mm}$ and a cross section of $30 \mathrm{~mm} \times 30 \mathrm{~mm}$ were cut using wire electrical discharge machining (wire-EDM).

The billets were processed with 4 passes of ECAP at $300^{\circ} \mathrm{C}$, using a die angle of $90^{\circ}$ with a sharp corner, 
at the rate of $1 \mathrm{~mm} / \mathrm{s}$. Route $\mathrm{Bc}$ was selected as the ECAP processing route. Route $\mathrm{Bc}$ consists in the alternating rotation of the billets by $90^{\circ}$ counterclockwise for each successive pass. During this process, the ECAP billets were coated with a graphite-based lubricant before each step.

Samples for the tensile tests were machined with a wireEDM cut from a billet, where their tensile axis was oriented parallel to the extrusion direction. The tensile test sample geometry is shown in Fig. 1. The tensile tests of the untreated and ECAP-treated samples were performed at a strain rate of $5 \times 10^{-4} / \mathrm{s},{ }^{13}$ each on 3 samples. The tensile tests were conducted using the Instron 8872 universal testing machine (Instron, Norwood, USA) with an optical extensometer, at room temperature.

Transmission electron microscopy and OM were used to investigate the microstructures of the ECAP-treated and untreated samples. The sample for OM was prepared using standard polishing techniques, and then etched with Kroll's reagent $\left(3 \mathrm{~mL} \mathrm{HF}+6 \mathrm{~mL} \mathrm{HNO}_{3}\right.$ in $100 \mathrm{~mL}$ of distilled water). ${ }^{19}$ The TEM sample was produced using FIB (Nova NanoLab 600i; Thermo Fisher Scientific, Waltham USA) with the dimensions $10 \mu \mathrm{m} \times 3 \mu \mathrm{m} \times 1 \mu \mathrm{m}$. The TEM (IEF30; Shinei Tecno Co., Ltd., Tokyo, Japan) observations were conducted at a nominal voltage of $300 \mathrm{kV}$.

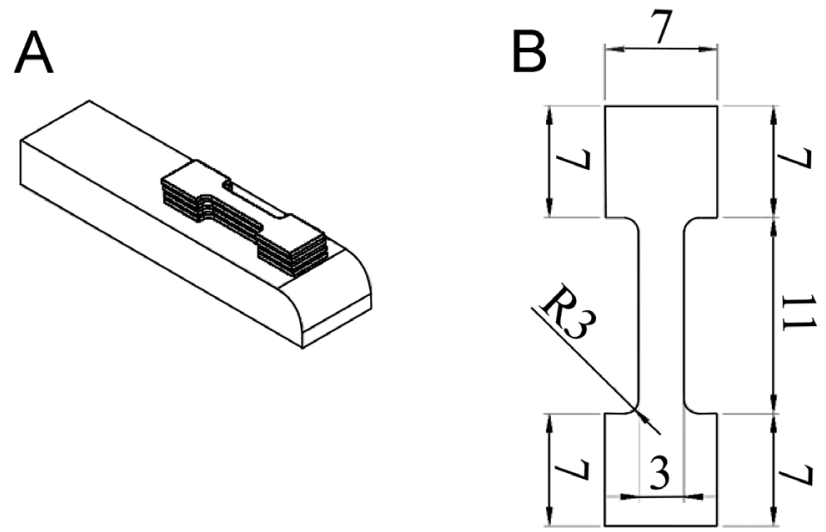

Fig. 1. Schematic representation of the extruded billets and the orientation of the tensile test samples $(A)$, and the tensile test sample dimensions [mm] (B)

In this study, 2 geometries of miniplate implants (TST Medical Devices, Istanbul, Turkey) were investigated. The miniplate implants were manufactured from the untreated and ECAP-treated materials. The dimensions and orientation of the miniplate implants are shown in Fig. 2.

Sixty synthetic polyurethane hemimandible replicas (model No. 8596; Synbone AG, Malans, Switzerland), having medullar and cortical portions, were used as 4 groups $(n=15)$. To simulate a hemimandible fracture, an acrylic-resin template was used in the mandibular angle region.

The fixation groups used in the study are presented in Table 1.

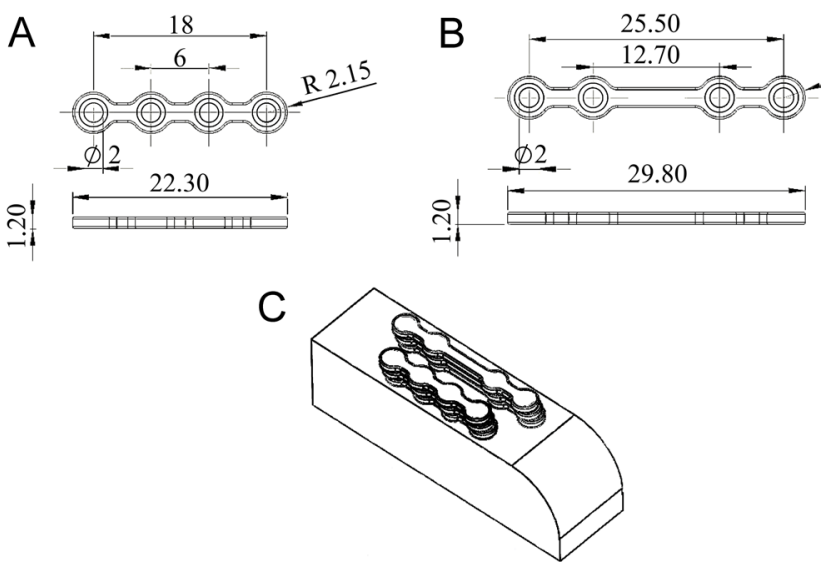

Fig. 2. Dimensions [mm] of the miniplates - regular (A) and long (B) - and their orientation (C)

Table 1. Fixation groups

\begin{tabular}{|c|c|}
\hline Group & Miniplate used in the fixation system \\
\hline Group 1 & regular miniplate produced from the untreated CP Ti \\
Group 2 & regular miniplate produced from the ECAP-treated CP Ti \\
Group 3 & long miniplate produced from the untreated CP Ti \\
Group 4 & long miniplate produced from the ECAP-treated CP Ti \\
\hline
\end{tabular}

CP - commercially pure; ECAP - equal-channel angular pressing.

The hemimandibles were fixed with 4 different miniplates, which were then stabilized with a support apparatus. The 2-point and 3-point bending and torsion tests were performed within the scope of this study to simulate the forces which the muscles transmit to the bone during chewing or the movement of the mandible. ${ }^{26}$

The AG-IS universal testing machine (Shimadzu, Kyoto, Japan) was used for the 2-point and 3-point bending tests (Fig. 3). A vertical compression force was applied at a rate of $2 \mathrm{~mm} / \mathrm{min} .{ }^{27}$ The tests were recorded with a camera recording system (5 images per second).

The torsion tests were performed using the NDW-200 machine (Jinan Liangong Testing Technology Co., Ltd., Jinan, China). The torsional force was applied to the rotating side at a rate of $5^{\circ} / \mathrm{min}$ (Fig. 4). ${ }^{28}$ The torsion test continued until the rotation angle reached $30^{\circ}$.

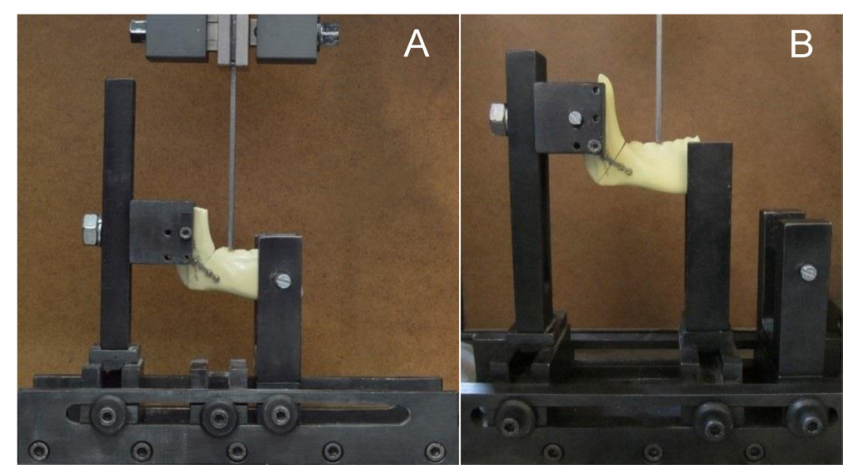

Fig. 3. Hemimandible models fixed to the supporting base for the 3-point (A) and 2-point (B) tests 


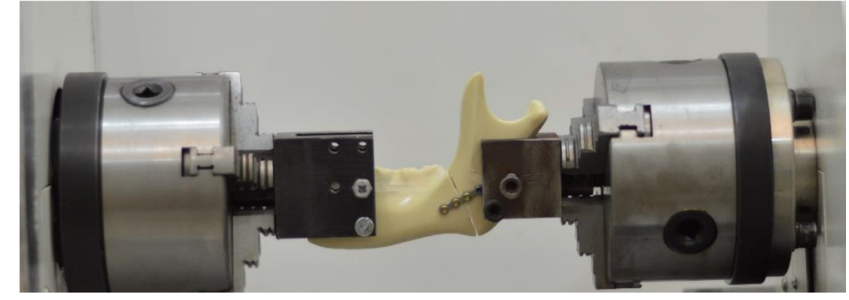

Fig. 4. Arrangement for the torsion test

\section{Results}

Figure $5 \mathrm{~A}$ shows an optical micrograph of the untreated CP Ti grade 2. The grain size distribution was not homogeneous and the average grain size was determined as $110 \mu \mathrm{m}$. A TEM micrograph of the ECAP-treated billet is shown in Fig. 5B. The preparation of the TEM sample using FIB is shown in Fig. 5C and 5D. The grain size of the ECAP-treated CP Ti grade 2 was $\sim 200 \mathrm{~nm}$.

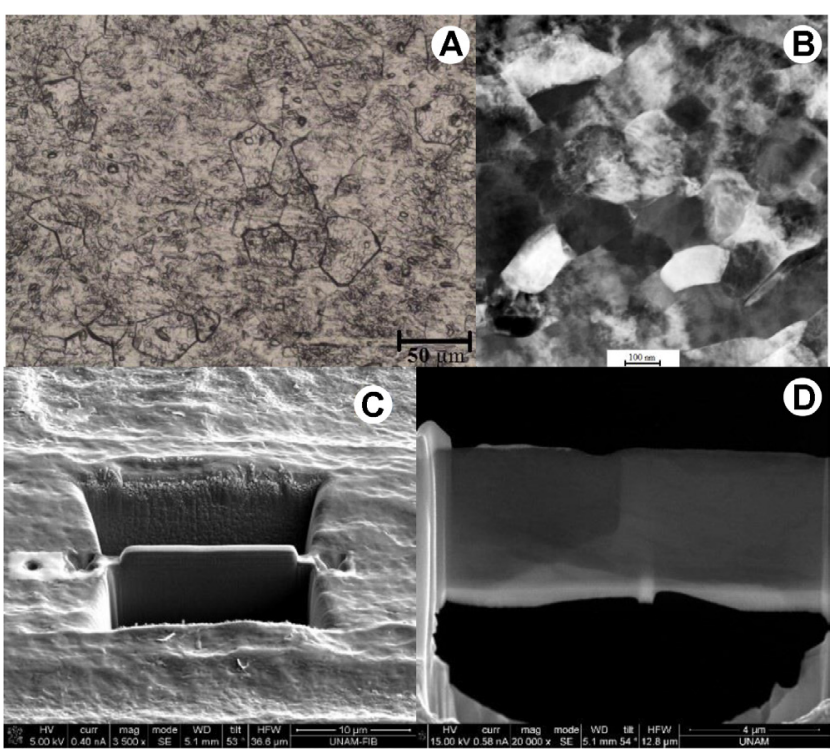

Fig. 5. Optical micrograph of the untreated CP Ti grade 2 (A), the transmission electron microscopy (TEM) micrograph of the ECAP-treated CP Ti grade 2 (B) and the TEM sample (C,D)

The engineering stress-strain curves and the tested samples of CG and UFG Ti are shown in Fig. 6. These curves indicate that, while ECAP processing increased the strength, it also caused a reduction in the overall elongation. The yield strength of CP Ti grade 2, which corresponds to $0.02 \%$ plastic deformation, considerably improved after 4 passes of ECAP. The yield stress increased from $\sim 310 \mathrm{MPa}$ to $\sim 650 \mathrm{MPa}$ after the ECAP process. On the other hand, the tensile stress increased from $\sim 535$ $\mathrm{MPa}$ to $\sim 795 \mathrm{MPa}$. After the ECAP process, the failure strain of the CP Ti grade 2 decreased from $32 \%$ to $19 \%$.

A ductile fracture was observed after the tensile test of the untreated and ECAP-treated samples. Also, SEM images of the fractured surfaces were investigated. They are presented in Fig. 7.

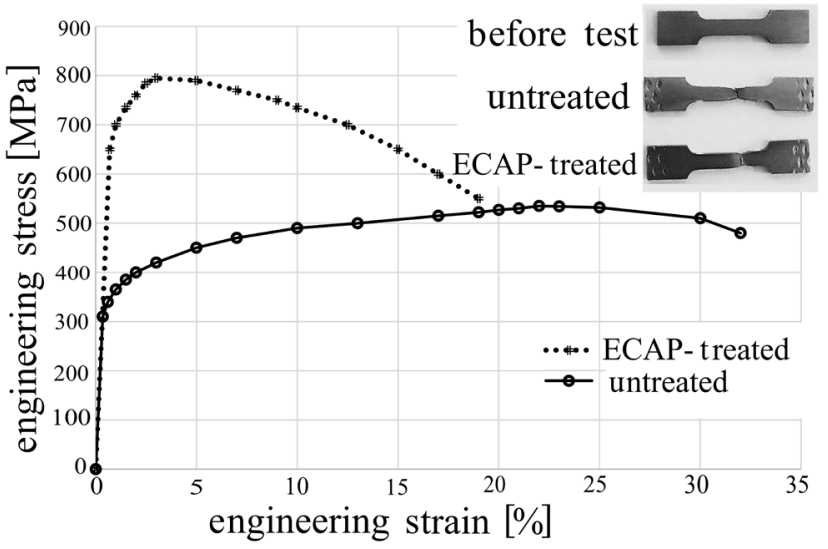

Fig. 6. Engineering stress-strain curves of the untreated and ECAP-treated CP Ti grade 2

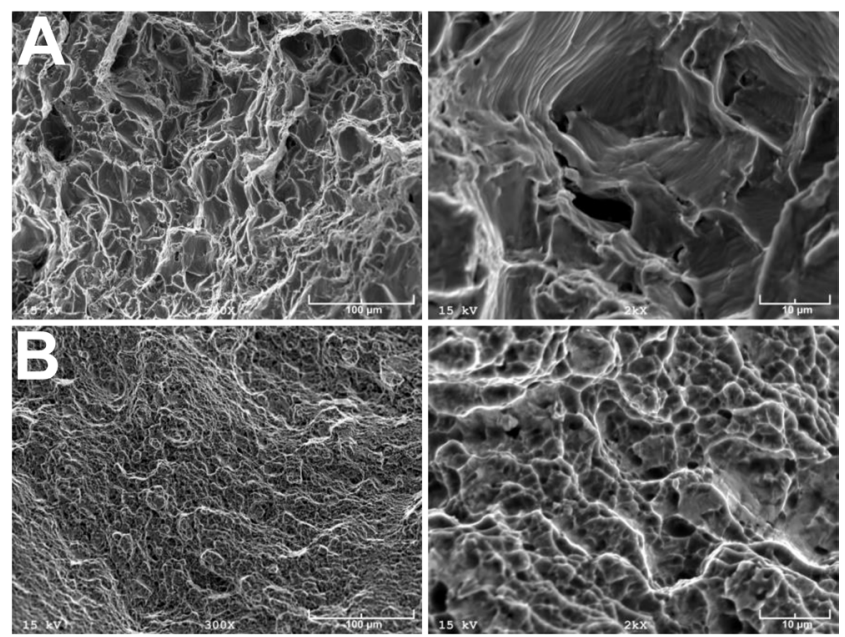

Fig. 7. Scanning electron microscopy (SEM) images of the untreated (A) and ECAP-treated (B) CP Ti grade 2

The force-displacement curves of the 2-point and 3 -point bending tests after the application of a compressive load on the hemimandible models with different plate systems are shown in Fig. 8 and Fig. 10, respectively.

Figure 8 presents the strength in the 2 -point bending tests. When this graph is examined, the regular and long miniplates produced from the untreated CP Ti show lower strength than the regular and long miniplates produced from the ECAP-treated CP Ti. The fixation model with the long miniplates produced from the untreated CP Ti material displaced $10 \mathrm{~mm}$ under a load of $\sim 50 \mathrm{~N}$. Under the same load, the long miniplate fixation system produced from the ECAP-treated CP Ti moved $4 \mathrm{~mm}$. In addition, the fixations established with the long miniplates produced from the ECAP-treated material endured to $125 \mathrm{~N}$. It can be seen that the fixation system established with the regular miniplates produced from the untreated $\mathrm{CP} \mathrm{Ti}$ material displaced $10 \mathrm{~mm}$ under a load of $85 \mathrm{~N}$. This value was $7 \mathrm{~mm}$ in the fixation system with the regular miniplates produced from ECAP-treated CP Ti. Also, the fixation systems which had the regular miniplates produced from the ECAP-treated material exhibited a strength of up to $\sim 139 \mathrm{~N}$. The images taken during the tests are presented as Fig. 9. 


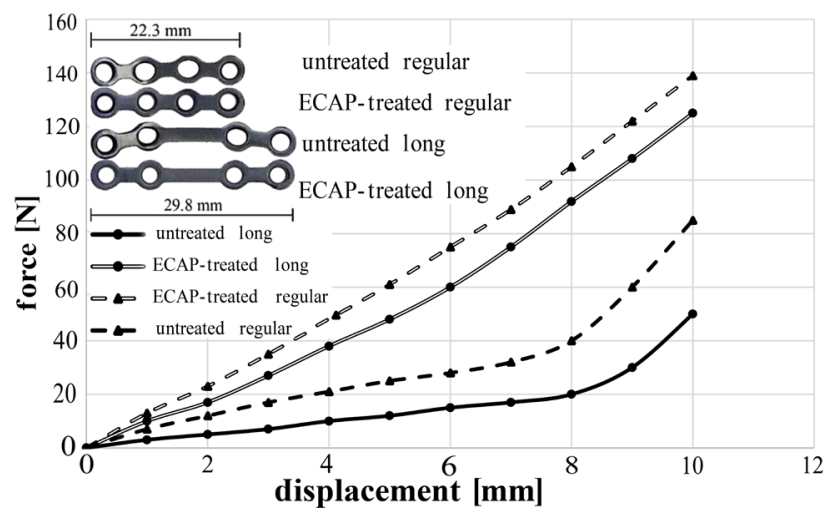

Fig. 8. Force-displacement curves of the 2-point bending tests

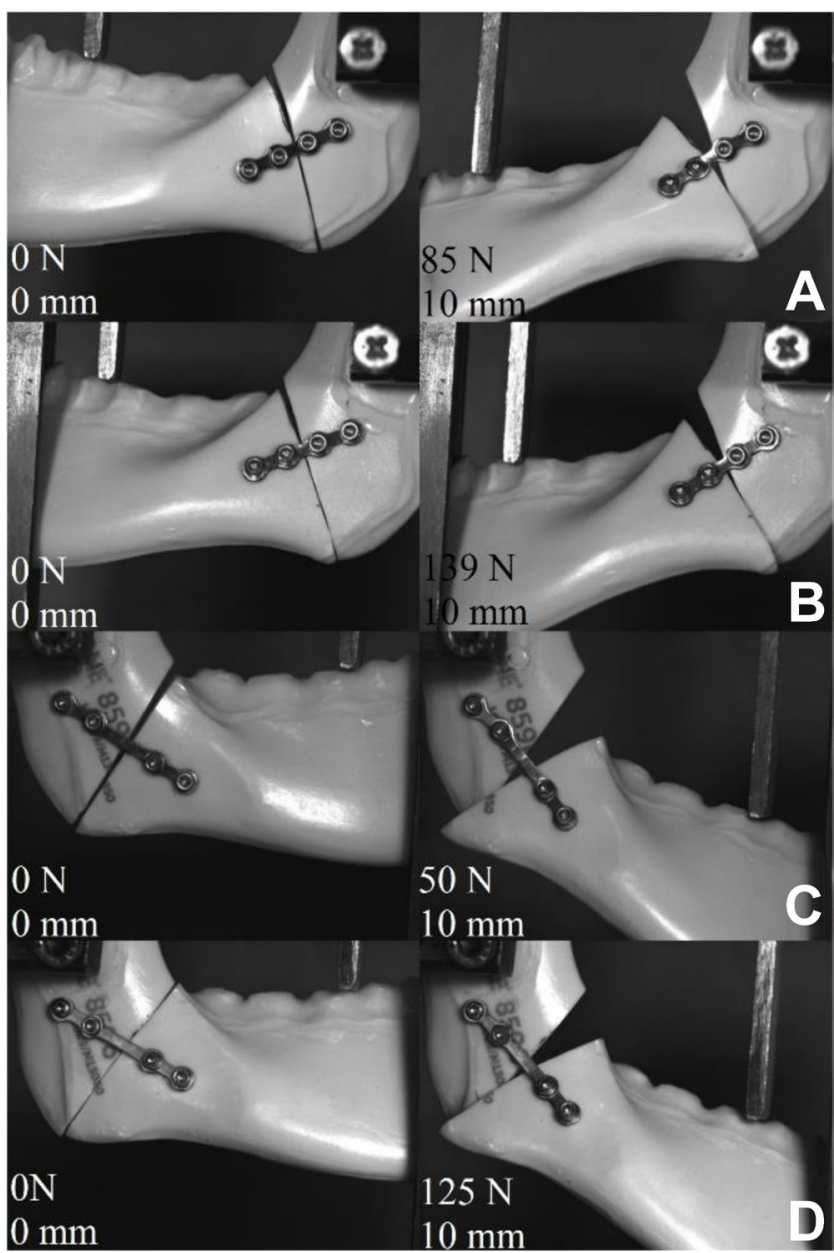

Fig. 9. Fixation systems after and before the 2-point bending tests

A - untreated-regular; B - ECAP-treated-regular; C - untreated-long;

$D$ - ECAP-treated-long.

Figure 10 shows the 3 -point bending test results of the miniplates produced from the untreated and ECAP-treated materials. From this graph, it can be seen that the ECAPtreated miniplates are more durable than the miniplates produced from the untreated material, as in the 2-point bending test. The fixation system established with the long miniplates produced from the untreated material displaced $10 \mathrm{~mm}$ under a load of $\sim 330 \mathrm{~N}$. The fixation system established with the long miniplates produced from the ECAP-treated material displaced $5 \mathrm{~mm}$ under the same load. In addition, the fixation system with the long miniplates produced from the ECAP-treated material endured to $590 \mathrm{~N}$. When the fixation systems established with regular miniplates were examined, those with the regular miniplates produced from the untreated material displaced $7 \mathrm{~mm}$ at $\sim 395 \mathrm{~N}$. This value was $\sim 4.5 \mathrm{~mm}$ for the fixation system with the regular miniplates produced from the ECAP-treated material. Also, the fixation system established with the regular miniplates produced from the ECAP-treated material endured to $\sim 515 \mathrm{~N}$. The images taken during the tests are given in Fig. 11.

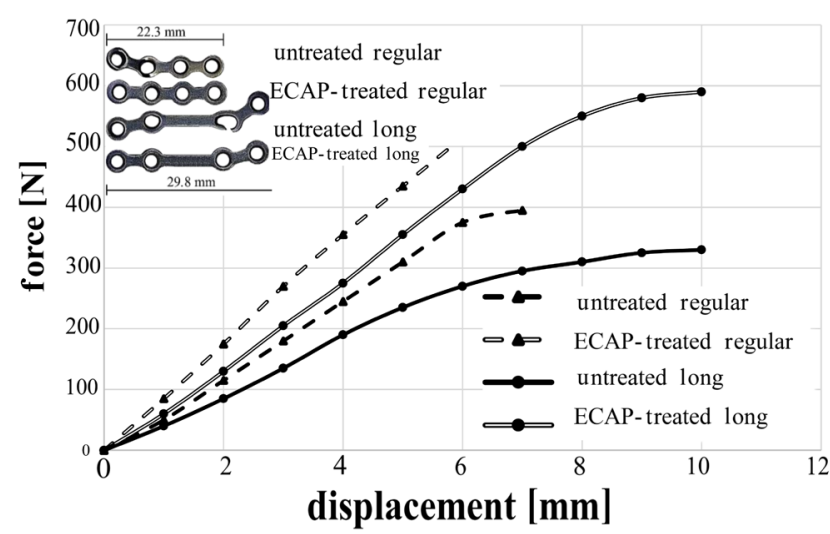

Fig. 10. Force-displacement curves of the 3-point bending tests

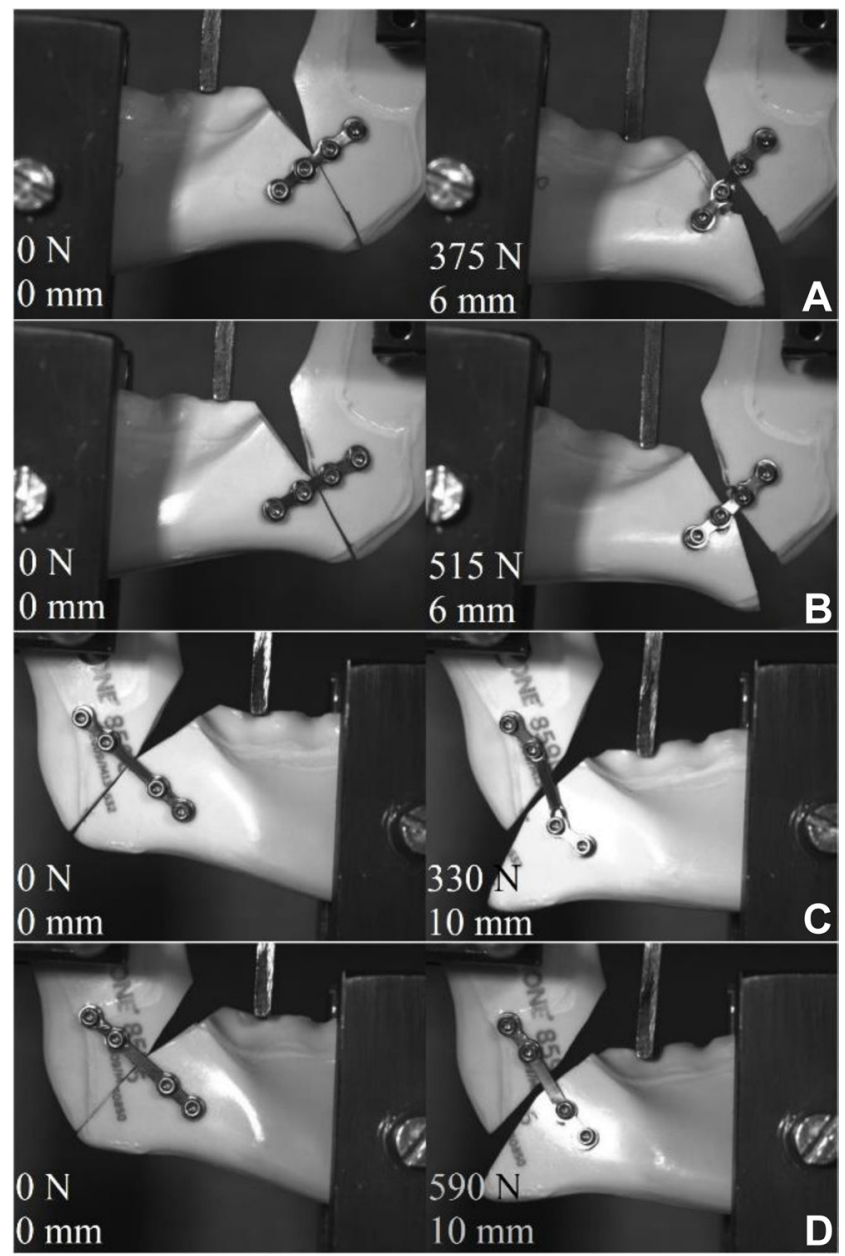

Fig. 11. Fixation systems after and before the 3-point bending tests A - untreated-regular; B - ECAP-treated-regular; C - untreated-long; $D$ - ECAP-treated-long. 
Figure 12 shows the loads corresponding to a 6-millimeter displacement during the 2-point and 3-point bending tests. According to these results, the ECAP-treated miniplates carried more load for both geometries. These results were especially related to a decrease in the grain size and an increase in the strength of the structure after the ECAP process. Also, the fixations established with regular miniplates were more durable within the same displacements than those with long miniplates. This behavior could be explained by greater movements on the long miniplate due to the area of the longer bar.

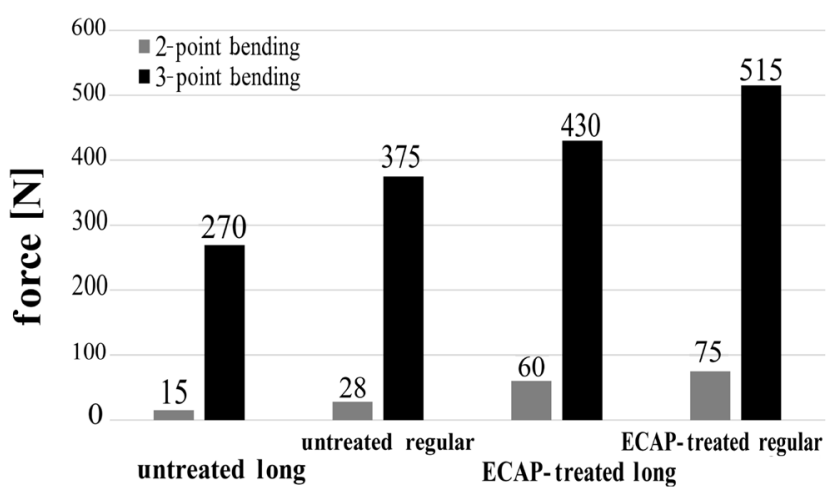

Fig. 12. Loads corresponding to a 6-millimeter displacement during the 2-point and 3-point bending tests

As explained above, using 2 miniplates increased the rigidity approx. two-fold. In this study, the stability was increased up to $400 \%$ in the 2-point bending test and $60 \%$ in the 3-point bending test after the ECAP process. For this reason, using the ECAP-treated miniplates ensures that higher rigidity can be achieved with fewer plates. Thus, for a surgical operation, it is possible to reduce the area of incision and shorten the healing time due to fewer screw holes in the mandible.

Figure 13 shows the torsion test results for different fixation models. The fixation systems established with the untreated long miniplates experienced $30^{\circ}$ rotational deformations under the 0.22 N.m torque, while the fixation systems established with the ECAP-treated long

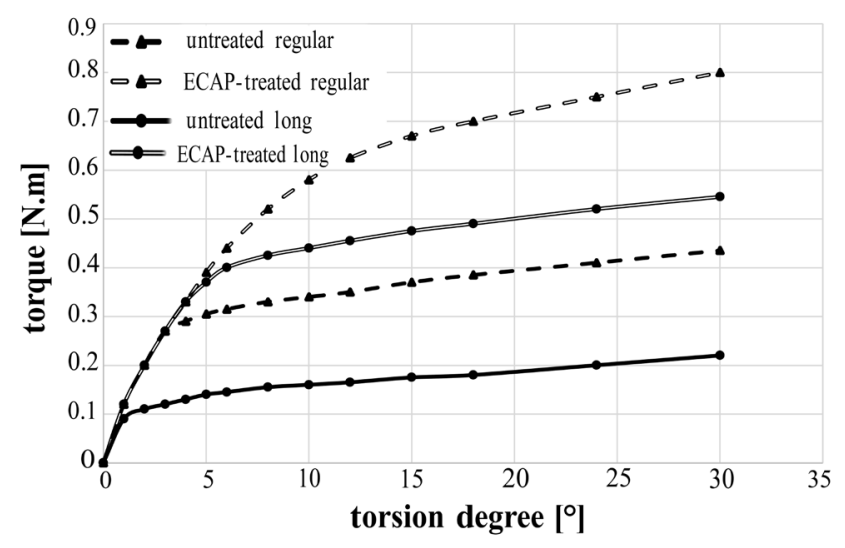

Fig. 13. Torque-rotation curves for the 4 fixation models miniplates exhibited $3^{\circ}$ deformations under the same torque value. In addition, the fixation systems with the ECAP-treated long miniplates endured to $\sim 0.545$ N.m. When the fixation systems established with regular miniplates were examined, the untreated regular miniplates showed $\sim 30^{\circ}$ contortion at $\sim 0.435$ N.m. This value was $\sim 6^{\circ}$ for the ECAP-treated regular miniplates. Moreover, the fixation systems established with the ECAP-treated regular miniplates endured to 0.8 N.m (Fig. 14). These results indicate that the miniplates produced from the ECAP-treated material are more durable in the torsion test than the untreated miniplates, and thus more rigid.

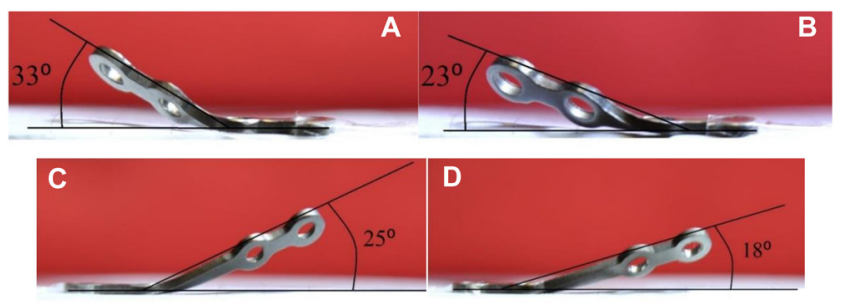

Fig. 14. Miniplates after the torsion tests

A - untreated-regular; B - ECAP-treated-regular; C - untreated-long; $D$ - ECAP-treated-long.

\section{Discussion}

The micrographs of the samples showed that 4 passes of the ECAP treatment led to a significant refinement in the microstructure of CP Ti grade 2 and transformed the untreated structure to the UFG structure. The grain size is influenced by the process temperature, deformation rate and die channel angle after the ECAP process. In the literature, it has been determined that the grain size after the ECAP treatment is in the range of 100-250 nm. Meredith and Khan obtained similar results after a 4-pass ECAP process on the Ti material. ${ }^{29}$

In the process of $S P D$, grain refinement begins with the transmutation of wide-angled grain boundaries into subgrains through the sliding mechanism. In addition, due to SPD, grains are broken to smaller ones. As seen in the TEM picture, no elongation occurred in the grains. Also, in CP Ti after 4 passes, the ECAP-treated grains are more homogeneously distributed as compared to the internal structure of the untreated grains. The reason of the homogeneous dispersion of the grains is that a 4-pass ECAP process is a complete turn of the deformation cycle.

The reasons for the improvement of the mechanical properties are excessive grain refining and increasing dislocations. Titanium, which has wide-angled ultrafine grains, blocks dislocation movements, and this increases strength. After stress reaches the maximum level, the untreated pure Ti exhibits a large strain neck area. Also, the heterogeneous deformation area is larger than the 
homogeneous area. After the ECAP treatment, while the yield and tensile strength of pure Ti increase, the homogeneous deformation area is reduced, but the heterogeneous deformation area is still in the range of processibility. Hence, the deformability of the material is helpful for the surgeon during an operation. ${ }^{30}$

Coaxial grooves and traces of plastic deformations are highly visible at the fracture sections. The examination of the grain size after the ECAP process showed that the coaxial cavity dimensions in the fracture images of these samples were smaller than in the untreated Ti.

Experimental studies with the 2-point bending tests have been carried out to achieve lesser displacement of the fracture region under load for different miniplate geometries and mounting positions. ${ }^{5,13}$ The fixations established with a double miniplate at the $5 \mathrm{~mm}$ displacement showed $140 \%$ higher load than the fixations established with a single miniplate. ${ }^{13}$ According to the results of this study, the fixation with the miniplate made from the ECAP-treated material at a displacement value of $5 \mathrm{~mm}$ endured $300 \%$ more than the fixation with the untreated miniplate. ${ }^{13}$

The studies which used the 3-point bending tests were conducted to obtain a more rigid fixation by changing the miniplate geometry, position and number. RibeiroJunior et al. used sagittal miniplates with different geometries and found that a sagittal-locked miniplate exhibited a more stable fixation than 4-hole and 6-hole locked and unlocked normal miniplates. ${ }^{31}$ In another study, RibeiroJunior et al. used locked and unlocked miniplates with 4 and 8 holes for fixations in the angular region. ${ }^{32}$ The 3 -point bending tests were applied to the fixation systems. As a result of the study, they found that the locked fixation system with 8 holes was more rigid than the others. ${ }^{32}$ Nieblerová et al. used miniplates having the same geometry in single and double miniplate applications at 2 different positions; then, the 3-point bending tests were performed on the samples. ${ }^{33}$ The authors reported that they achieved a more stable fixation when using a double miniplate. When these results were examined, it was seen that there was $55 \%$ less displacement in the fixation established using a double-bar miniplate under the $100 \mathrm{~N}$ load. ${ }^{33}$ In our study, the fixation with the ECAP-treated miniplate was found to be $40 \%$ more rigid than the fixation which used the untreated miniplate.

The number of studies on the examination of the torsional force on the mandible is limited. However, when considering the geometry of the mandibular bone and the muscle forces acting on it, the torsional load has a significant role in curing mandibular fractures. When a load is applied on the opposite side of a fractured mandible, the torsional moment will occur. Feller et al. established different fixation systems, using microplates and miniplates, and then performed the torsion tests. ${ }^{28}$ As a result of the study, they found that using a miniplate and a microplate in the same fixation made it more rigid as compared to single-miniplate or single-microplate fixations. ${ }^{28}$ In addition, due to the torsional moments which occur in the mini-screw because of torsion, screw loosening affects the patient's healing time. According to Champy, due to the moments which occur in the anterior region of the mandible, fixations should endure up to 1,000 N.m. acc.28 $^{\text {act }}$ When the results of Feller et al. were examined, it was seen that the fixation established with a double miniplate was 4.25 times less displaced at $700 \mathrm{~N} . \mathrm{mm}$ than the fixation established with a single miniplate. ${ }^{28}$ In our study, it was observed that the fixations established with the miniplate produced from the ECAP-processed material were displaced 4.8 times less as compared to the fixations established with the untreated miniplate.

\section{Conclusions}

This study showed that fixation systems become more rigid when ECAP-treated miniplates are used, and this ensures lesser displacement of the fixation system. These results rely on the ECAP process, which causes the grain size to decrease and strength to increase. Due to these benefits, ECAP-treated miniplates exhibit more rigid behavior than their untreated equivalents. Along with this, ECAP-treated miniplates proved to be a suitable substitution for multiple miniplate fixations.

\section{ORCID iDs}

Hojjat Ghahramanzadeh Asl (D) https://orcid.org/0000-0002-9078-1933 Akgün Alsaran (D) https://orcid.org/0000-0002-3258-2469

\section{References}

1. Hayter JP, Cawood JI. The functional case for miniplates in maxillofacial surgery. Int J Oral Maxillofac Surg. 1993;22(2):91-96. doi:10.1016/s09015027(05)80810-0

2. Regev E, Shiff JS, Kiss A, Fialkov JA. Internal fixation of mandibular angle fractures: A meta-analysis. Plast Reconstr Surg. 2010;125(6):1753-1760. doi:10.1097/PRS.0b013e3181d0a9fc

3. Dogru SC, Cansiz E, Arslan YZ. Biomechanical evaluation of resorbable and titanium miniplates and of single and double miniplates for the treatment of mandibular condyle fractures. Biocybern Biomed Eng. 2019;39(3):709-718. doi:10.1016/j.bbe.2019.04.006

4. Sukegawa S, Kanno T, Masui M, et al. Which fixation methods are better between three-dimensional anatomical plate and two miniplates for the mandibular subcondylar fracture open treatment? J Craniomaxillofac Surg. 2019;47(5):771-777. doi:10.1016/j.jcms.2019.01.033

5. Oh JS, Kim SG. In vitro biomechanical evaluation of fixation methods of sagittal split ramus osteotomy in mandibular setback. J Craniomaxillofac Surg. 2015;43(2):186-191. doi:10.1016/j.jcms.2014.10.023

6. Esen A, Dolanmaz D, Tüz HH. Biomechanical evaluation of malleable noncompression miniplates in mandibular angle fractures: An experimental study. Br J Oral Maxillofac Surg. 2012;50(5):e65-e68. doi:10.1016/j.bjoms.2011.10.013

7. Yener O, Saglam H, Dolanmaz D, Uckan S. Comparison of stability of $2.0 \mathrm{~mm}$ standard and $2.0 \mathrm{~mm}$ locking miniplate/screws for the fixation of sagittal split ramus osteotomy on sheep mandibles. Br J Oral Maxillofac Surg. 2011;49(2):135-137. doi:10.1016/j.bjoms.2009.11.014

8. Bayram B, Araz K, Uckan S, Balcik C. Comparison of fixation stability of resorbable versus titanium plate and screws in mandibular angle fractures. J Oral Maxillofac Surg. 2009;67(8):1644-1648. doi:10.1016/j.joms.2009.03.011 
9. Zimmermann C, Henningsen A, Henkel KO, et al. Biomechanical comparison of a multidirectional locking plate and conventional plates for the osteosynthesis of mandibular angle fractures - a preliminary study. J Craniomaxillofac Surg. 2017;45(12):1913-1920. doi:10.1016/j.jcms.2017.05.020

10. Darwich MA, Albogha MH, Abdelmajeed A, Darwich K. Assessment of the biomechanical performance of 5 plating techniques in fixation of mandibular subcondylar fracture using finite element analysis. JOral Maxillofac Surg. 2016;74(4):794.e1-e8. doi:10.1016/j.joms.2015.11.021

11. Esen A, Ataoğlu H, Gemi L. Comparison of stability of titanium and absorbable plate and screw fixation for mandibular angle fractures. Oral Surg Oral Med Oral Pathol Oral Radiol Endod. 2008;106(6):806-811. doi:10.1016/j.tripleo.2008.05.034

12. Trivellato PFB, Pepato AO, Ribeiro MC, Sverzut CE, Trivellato AE. In vitro evaluation of the resistance of a $2.0-\mathrm{mm}$ titanium fixation system in the sectioned angle without continuity of the inferior border of the mandible. Int J Oral Maxillofac Surg. 2014;43(5):559-563. doi:10.1016/j.ijom.2013.10.002

13. Oguz Y, Watanabe ER, Reis JM, Spin-Neto R, Gabrielli MA Pereira-Filho VA. In vitro biomechanical comparison of six different fixation methods following $5-\mathrm{mm}$ sagittal split advancement osteotomies. Int J Oral Maxillofac Surg. 2015;44(8):984-988. doi:10.1016/j.ijom.2014.11.019

14. Gonzales DMC, Spagnol G, Sverzut CE, Trivellato AE. In vitro evaluation of the resistance of three types of fixation to treat fractures of the mandibular angle. Br J Oral Maxillofac Surg. 2017;55(2):136-140. doi:10.1016/j.bjoms.2016.09.017

15. Sittitavornwong S, Denson D, Ashley D, Walma DC, Potter S, Freind J. Integrity of a single superior border plate repair in mandibular angle fracture: A novel cadaveric human mandible model. J Oral Maxillofac Surg. 2018;76(12):2611.e1-2611.e8. doi:10.1016/j.joms.2018.07.029

16. Arbag H, Korkmaz HH, Ozturk K, Uyar Y. Comparative evaluation of different miniplates for internal fixation of mandible fractures using finite element analysis. J Oral Maxillofac Surg. 2008;66(6):1225-1232. doi:10.1016/j.joms.2005.11.092

17. Hajizadeh K, Eghbali B, Topolski K, Kurzydlowski KJ. Ultra-fine grained bulk CP-Ti processed by multi-pass ECAP at warm deformation region. Mater Chem Phys. 2014;143(3):1032-1038. doi:10.1016/j. matchemphys.2013.11.001

18. Rosochowski A. Processing metals by severe plastic deformation. Solid State Phenom. 2005;101-102:13-22. doi:10.4028/www.scientific. net/SSP.101-102.13

19. Purcek G, Yapici GG, Karaman I, Maier HJ. Effect of commercial purity levels on the mechanical properties of ultrafine-grained titanium. Mater Sci Eng A. 2011;528(6):2303-2308. doi:10.1016/j.msea.2010.11.021

20. Iwahashi Y, Wang J, Horita Z, Nemoto M, Langdon TG. Principle of equal-channel angular pressing for the processing of ultra-fine grained materials. Scr Mater. 1996;35(2):143-146. doi:10.1016/1359-6462(96)00107-8
21. Figueiredo RB, de C. Barbosa ER, Zhao X, et al. Improving the fatigue behavior of dental implants through processing commercial purity titanium by equal-channel angular pressing. Mater Sci Eng A. 2014;619:312-318. doi:10.1016/j.msea.2014.09.099

22. Valiev RZ, Islamgaliev RK, Alexandrov IV. Bulk nanostructured materials from severe plastic deformation. Prog Mater Sci. 2000;45(2):103-189. doi:10.1016/S0079-6425(99)00007-9

23. Valiev RZ, Semenova IP, Latysh VV, et al. Nanostructured titanium for biomedical applications. Adv Eng Mater. 2008;10(8):B15-B17. doi:10.1002/adem.200800026

24. Estrin Y, Kim HE, Lapovok R, Ng HP, Jo JH. Mechanical strength and biocompatibility of ultrafine-grained commercial purity titanium. Biomed Res Int. 2013;2013:914764. doi:10.1155/2013/914764

25. Polyakov AV, Semenova IP, Valiev RZ. High fatigue strength and enhanced biocompatibility of UFG CP Ti for medical innovative applications. Mater Sci Eng. 2013;63:012113. doi:10.1088/1757899X/461/1/012077

26. Rudderman RH, Mullen RL, Phillips JH. The biophysics of mandibular fractures: An evolution toward understanding. Plast Reconstr Surg. 2008;121(2):596-607. doi:10.1097/01.prs.0000297646.86919.b7

27. Hakim SG, Wolf M, Wendlandt R, Kimmerle H, Sieg P, Jacobsen HC. Comparative biomechanical study on three miniplates osteosynthesis systems for stabilisation of low condylar fractures of the mandible. $\mathrm{Br} J \mathrm{Oral}$ Maxillofac Surg. 2014;52(4):317-322. doi:10.1016/j.bjoms.2014.02.002

28. Feller KU, Richter G, Schneider M, Eckelt U. Combination of microplate and miniplate for osteosynthesis of mandibular fractures: An experimental study. Int J Oral Maxillofac Surg. 2002;31(1):78-83. doi:10.1054/ijom.2000.0182

29. Meredith CS, Khan AS. The microstructural evolution and thermomechanical behavior of UFG Ti processed via equal channel angular pressing. J Mater Process Technol. 2015;219:257-270. doi:10.1016/j. jmatprotec.2014.12.024

30. Shikinami Y, Okuno M. Bioresorbable devices made of forged composites of hydroxyapatite (HA) particles and poly l-lactide (PLLA). Part II: Practical properties of miniscrews and miniplates. Biomaterials. 2001;22(23):3197-3211. doi:10.1016/s0142-9612(01)00072-2

31. Ribeiro-Junior PD, Magro-Filho O, Shastri KA, Papageorge MB. Which kind of miniplate to use in mandibular sagittal split osteotomy? An in vitro study. Int J Oral Maxillofac Surg. 2012;41(11):1369-1373. doi:10.1016/j.ijom.2012.05.003

32. Ribeiro-Junior PD, Magro-Filho O, Shastri KA, Papageorge MB. In vitro evaluation of conventional and locking miniplate/screw systems for the treatment of mandibular angle fractures. Int J Oral Maxillofac Surg. 2010;39(11):1109-1114. doi:10.1016/j.ijom.2010.06.019

33. Nieblerová J, Foltán R, Hanzelka T, et al. Stability of the miniplate osteosynthesis used for sagittal split osteotomy for closing an anterior open bite: An experimental study in mini-pigs. Int J Oral Maxillofac Surg. 2012;41(4):482-488. doi:10.1016/j.ijom.2011.11.005 